\title{
Die Aard en Voorkoms van Middeloorpatologieë in Laerskole vir Normaalhorende Blanke Kinders
}

\author{
Carin Cilliers, B Log (Pretoria)* \\ Deon P Rossouw, MB Ch B M Med (ORL) (Pretoria) \\ Santie Meyer, M Log (Pretoria)* $^{*}$ \\ Marina Hurter, B Log (Pretoria)* \\ *Departement Spraakheelkunde, Spraakwetenskap en Oudiologie, \\ Universiteit van Pretoria \\ Departement Oor-, Neus- en Keelheelkunde, \\ Universiteit van Pretoria
}

\section{OPSOMMING}

Die doel van hierdie studie is om vas te stel wat die aard en voorkoms van middeloorprobleme by graad 1 en 2 blanke kinders is. Siftingsoudiometrie is op 50 leerlinge (100 ore), in 'n hoë, en 50 leerlinge (100 ore) in 'n lae sosio-ekonomiese omgewing uitgevoer. Alle leerlinge wat 'n eerste oudiometriese siftingsprosedure gefaal het, is aan 'n tweede siftingsprosedure onderwerp. Uit die resultate blyk dit dat 19,5\% uitgeval het op die oudiologiese siftingstoetse. ' $n$ Otologiese ondersoek het $8,5 \%$ van hierdie kinders geidentifiseer as kinders met middeloorprobleme. Daar was nie statisties beduidende verskille tussen die verskillende sosio-ekonomiese groepe nie.

\section{ABSTRACT}

The aim of the study was to determine the prevalence of middle ear dysfunction amongst grade 1 and 2 white children. Identification audiometry was performed on 50 children (100 ears) in a high, and 50 children (100 ears) in a low socio-economic area. All children failing the identification audiometric procedure were re-evaluated. The results indicated that $19,5 \%$ also failed the second audiometric screening. Of these children $8,5 \%$ were identified as children with middle ear problems. There were no statistically significant differences between the two socio-economic groups.

Voor die ouderdom van tien jaar het ongeveer $75 \%$ van alle kinders een of meer aanvalle van akute otitis media ondervind (Mbller, 1985). Juis aangesien daar so 'n hoë voorkoms van otitis media is, is vroeë identifisering, soos by enige gehoorpatologie, van groot belang. Die rede hiervoor is dat dit gevolge kan hê wat deur vroeë intervensie voorkom kan word. Met ander woorde, kinders wat herhaalde aanvalle van chroniese otitis media in die vroeë lewensjare gehad het, kan later as gevolg hiervan sekondêre probleme toon. Dit sluit onder andere in: vertraagde taalontwikkeling en versteurde taalvaardighede, ouditiewe perseptuele probleme, swak intellektuele vermoëns, swak akademiese prestasie en gedrags- en emosionele probleme (Hugo, 1984; Feldman en Wilber, 1977; Northern en Downs, 1984).

Die rede vir die negatiewe sekondêre gevolge van otitis media is dat kinders ' $n$ wisselende graad van ouditiewe deprivasie ondervind, as gevolg van die fluktuerende aard van die toestand. Sekere hoërisikogroepe is al geïdentifiseer, byvoorbeeld die gesplete-lip-en-verhemeltepopulasie (McWilliams, Morris en Shelton, 1984). Daar is byvoorbeeld ook uitgevind dat die voorkoms van otitis media opvallend hoër in die laer sosio-ekonomiese groepe as in die hoër sosioekonomiese groepe is (Klein, 1978). Dit kan waarskynlik aan verskeie faktore toegeskryf word, byvoorbeeld oorbevolking, swak sanitêre toestande, ontoereikende mediese dienste, wanvoeding, sosio-kulturele ongelykheid, lae motivering en swak algemene gesondheid (Lewis, 1976; Klein, 1978 .

Alhoewel daar reeds baie navorsing gedoen is ten opsigte van kindergehoorverliese in Eerste Wêreldlande, byvoorbeeld Swede, Engeland en die Verenigde State van Amerika, bestaan daar ' $n$ groot leemte ten opsigte van inligting oor Derde Wêreldlande (Wilson, 1985). Suid-Afrika, met die kenmerkende Eerste en Derde Wêreldomstandighede, vertoon ook 'n gebrek aan inligting ten opsigte van die prevalensie van oor-en gehoorpatologie. Geen studies in hierdie verband is al op die Suid-Afrikaanse Kaukasiese groepe (waaronder die blankes gereken word) gedoen nie.

Hierdie studie is dus ' $n$ poging om ten dele hierdie leemte te vul en vas te stel wat die voorkoms van middeloorpatologie onder Suid-Afrikaanse graad 1 en 2 blanke kinders is en ook om vas te stel of sosio-ekonomiese verskille wel 'n merkbare invloed uitoefen op die voorkoms van middeloorpatologieë.

\section{EKSPERIMENT}

Proefpersone

Blanke kinders woonagtig in Pretoria is geselekteer. Die 
kinders is in graad 1 en graad 2. Een groep besoek 'n skool wat in 'n lae sosio-ekonomiese gebied geleë is. Die ander groep besoek 'n skool in 'n hoë sosio-ekonomiese area (Van Bergen, 1982). Die kinders is deur middel van 'n gestratifiseerde ewekansige steekproef uit die 2 skole geselekteer.

Tabel 1: Voorstelling van proefpersone

\begin{tabular}{|c|c|c|c|}
\hline OUDERDOM & SKOOL $1^{*}$ & SKOOL $2^{* *}$ & TOTAAL \\
\hline 6 Jaar & 16 & 9 & 25 \\
7 Jaar & 34 & 35 & 69 \\
8 Jaar & 0 & 6 & 6 \\
\hline TOTAAL & 50 & 50 & \\
\hline
\end{tabular}

* Skool 1: Hoër sosio-ekonomiese status

** Skool 2: Laer sosio-ekonomiese status

\section{Apparaat}

Die otoskopiese ondersoek is deur middel van 'n Welch Allyn otoskoop en immittansiemetings deur middel van 'n Grason Stadler model GSI 28 Auto Tymp (geyk volgens 150-1975 standaarde) uitgevoer. Die suiwertoondrempels is met behulp van Madsen Electronics OB40 igeyk volgens SABS 082 standaardel bepaal en die agtergrondgeraas is met behulp van 'n Bruël en Kjaer 2204 klankpeilmeter gemeet.

\section{Prosedure}

Die eksperimentele metode is ' $n$ tweegroepontwerp wat ' $n$ tussengroep ontwerpmetode is (Smit, 1983).

$\mathrm{Al}$ die proefpersone is in April en Mei getoets aangesien klimaatverandering die resultate kan beïnvloed wanneer boonste lugweginfeksies in die wintermaande die voorkoms van die middeloorpatologie verhoog (Voogt, Halama \& van der Merwe, 1986).

Klankpeilmetings is van ' $n$ stil vertrek gemaak om te bepaal of dit geskik vir suiwertoonsiftingsdoeleindes is (Barrett, 1985). In beide skole was die agtergrondgeraas in die vertrek binne die voorgestelde perke en dus geskik vir siftingsoudiometrie.

'n Inisiële gehoorsifting is uitgevoer om kinders sonder mid. deloordisfunksie uit te skakel. Hiervoor is al die proefpersone aan 'n otoskopiese ondersoek en siftingsimmittansiemeting onderwerp. Slegs proefpersone wat nie die inisiële siftingstoets geslaag het nie, is aan opvolgtoetsing onderwerp.

Die opvolgtoetsing het bestaan uit 'n oor-, neus- en keelondersoek, uitgevoer deur 'n oor-, neus- en keelarts, siftingsimmittansiemetings en 'n suiwertoonsiftingsondersoek.

\section{Data-ontleding}

Die ondersoek van die timpaniese membraan is na aanleiding van die oor-, neus- en keelarts se bevindings as volg geklassifiseer:

I - Normaal, II - Geskend (fibroties, atrofies, skleroties), III - Kliniese otitis media (cholestiatoma, timpaniesemembraan-perforasie, middeloor-effusie, atelektatiese otitis media, akute otitis media).
Siftingsimmittansiemetings se slaag/faalkriteria is soos volg (ASHA in Barrett, 1985):

Klas I - slaag Middeloordruk tussen + 100 en - 200 daPa en ' $n$ teenwoordige akoestiese refleks.

Klas II - risiko Abnormale middeloordruk en teenwoordige akoestiese refleks of middeloordruk tussen +100 en -200 daPa en afwesige akoes. tiese refleks. Hertoets na drie tot vyf weke.

Klas III - faal Middeloordruk abnormaal en afwesige akoestiese refleks.

Die kriteria vir normale en afwykende timpanogramme is volgens Jerger $(1970)$ ter aanvulling van bogenoemde kriteria gebruik.

Suiwertoonsiftingskriteria is as volg (ASHA in Barrett, 1985):

Volgens dié standaarde moet proefpersone drempels hê van: $20 \mathrm{~dB}$ GP by $500 \mathrm{~Hz}_{1} 1000 \mathrm{~Hz}$ en $2000 \mathrm{~Hz}$ en $20 \mathrm{~dB}$ of $25 \mathrm{~dB}$ by $4000 \mathrm{~Hz}$.

Om te bepaal of die verskille tussen die twee-groepe proefpersone statisties beduidend is, is daar vandie volgende formule gebruik gemaak:

$$
\mathrm{Z}=\frac{\mathrm{P} 1-\mathrm{P} 2}{\sqrt{\mathrm{P}(\overline{1} \cdot \overline{\mathrm{P}})} \sqrt{1 / 00+\overline{1 / 1} \bar{\theta}}}
$$

Waardes is op die $1 \%$ peil van betekenis bereken.

\section{RESULTATE}

Tabel 2: Die ore wat die inisiële en opvolgimmitansiemetings slaag/faal

\begin{tabular}{|c|c|c|}
\hline & $\begin{array}{l}\text { FAAL INISIËLE } \\
\text { SIFTING }\end{array}$ & $\begin{array}{l}\text { FAAL OPVOLG- } \\
\text { SIFTING }\end{array}$ \\
\hline $\begin{array}{l}\text { SKOOL 1: } \\
\mathrm{N}=100\end{array}$ & $\begin{array}{l}29 / 100 \\
(29 \%)\end{array}$ & $\begin{array}{l}20 / 100 \\
|20 \%|\end{array}$ \\
\hline $\begin{array}{l}\text { SKOOL } 2: \\
\mathbf{N}=100\end{array}$ & $\begin{array}{l}24 / 100 \\
\{24 \%\}\end{array}$ & $\begin{array}{l}19 / 100 \\
(19 \%)\end{array}$ \\
\hline $\begin{array}{l}\text { TOTAAL: } \\
\mathbf{N}=200\end{array}$ & $\begin{array}{c}53 / 200 \\
\{26,5 \%\}\end{array}$ & $\begin{array}{c}39 / 200 \\
\{19,5)\end{array}$ \\
\hline
\end{tabular}

In tabel 2 word 'n vergelyking getref tussen die aantal ore wat die eerste sifting gefaal het en dié wat die tweede sifting gefaal het. Uit tabel 2 blyk dit dat $19,5 \%$ ore die tweede sifting gefaal het waar daar aanvanklik $26,5 \%$ ore gefaal het. Daar het dus meer leerlinge gefaal tydens die eerste toetsing as tydens die tweede toetsing. Hierdie verskynsel kan verklaar word as sou die middeloortoestande, wat in die eerste toetsing opgemerk is, ten tye van die tweede toetsing in sommige gevalle alreeds spontaan opgeklaar het-/Prescod, 1978). Hierdeur word oorverwysing dus verminder. Brooks (1976) waarsku ook daarteen dat te veel waarde aan 'n enkele abnormale timpanometriese uitslag geheg word en beklemtoon ook die groot mate van' spontane herstel wat voorkom.

Uit die resultate blyk dit verder dat die leerlinge in skool 1 
in 'n geringe mate swakker gevaar het as die leerlinge in skool 2 op beide siftingstoetse. Hierdie verskille is egter nie statisties betekenisvol nie $[\mathrm{z}=0,8<2,52$ maar $>-2,57$; $z=1,66<2,57$ maar $>-2,571$.

Hierdie tendens is moeilik verklaarbaar aangesien daar verwag is dat leerlinge vanuit die hoër sosio-ekonomiese groep minder middeloorprobleme sou vertoon as leerlinge vanuit die laer sosio-ekonomiese groep.

Redes hiervoor kan wees dat daar miskien nie so ' $\mathrm{n}$ groot verskil in sosio-ekonomiese status onder blankes in Pretoria is nie (Badenhorst, 1987). Verder beskik albei skole oor sowel skoolmediese dienste as oudiologiese dienste. Ten spyte van die relatief lae sosio-ekonomiese gebied waarin die proefpersone van skool 2 woonagtig is, is dit so dat heelwat van die inwoners by groot industrieë werksaam is wat goeie mediese fasiliteite bied. ' $n$ Laaste faktor wat die resultate kon beïnvloed, is die ouderdomme van die kinders. Leerlinge in skool 1 was effens jonger as dié in skool 2 . Aangesien jonger kinders 'n groter voorkoms van middeloorpatologie vertoon, kon dit duidelik die rede wees hoekom die resultate van die twee skole nie beduidend van mekaar verskil nie.

Ten einde te bepaal of die proefpersone wat met die siftingstoetse uitgeval het, wel oor die patologiese middeloorfunksie beskik, is die resultate van die otologiese ondersoeke in verband gebring met dié van die opvolgimmittansiemetings. Resultate kan soos volg getabelleer word:

Tabel 3: Die otologiese diagnose van die ore wat met die opvolgimmittansiemetings uitval

\begin{tabular}{|c|c|c|c|}
\hline & \multirow{2}{*}{$\begin{array}{c}\begin{array}{c}\text { OPVOLG- } \\
\text { SIFTING }\end{array} \\
\text { FAAL }\end{array}$} & \multicolumn{2}{|c|}{$\begin{array}{c}\text { OTOLOGIESE } \\
\text { DIAGNOSE }\end{array}$} \\
\hline & & \begin{tabular}{|c|}
$\begin{array}{c}\text { PATOLO- } \\
\text { GIES }\end{array}$ \\
\end{tabular} & NORMAAL \\
\hline $\begin{array}{c}\text { Skool } 1 \\
N=29\end{array}$ & $\begin{array}{l}20 / 29 \\
69 \%)\end{array}$ & $\begin{array}{c}11 / 29 \\
\{37,9 \%)\end{array}$ & $\begin{array}{c}9 / 29 \\
\mid 31 \%)\end{array}$ \\
\hline $\begin{array}{l}\text { Skool } 2 \\
N=24\end{array}$ & $\begin{array}{c}19 / 24 \\
|79,1 \%|\end{array}$ & $\begin{array}{c}6 / 24 \\
\{25 \%\} \\
\end{array}$ & $\begin{array}{c}13 / 24 \\
|54,2 \%|\end{array}$ \\
\hline $\begin{array}{l}\text { Totaal: } \\
\text { (Opvolgsifting) } \\
\mathrm{N}=53\end{array}$ & $\begin{array}{c}1 \\
39 / 53 \\
173,6 \%) \\
1 \\
1\end{array}$ & $\begin{array}{c}17 / 53 \\
(32,1 \%)\end{array}$ & $\begin{array}{c}22 / 53 \\
(41,5 \%)\end{array}$ \\
\hline $\begin{array}{l}\text { Totaal: (Uit totale } \\
\text { populasie) } \\
\mathrm{N}=200\end{array}$ & $\begin{array}{c}39 / 100 \\
\{19,5 \%\}\end{array}$ & $\begin{array}{l}17 / 200 \\
\{8,5 \% \mid\end{array}$ & $\begin{array}{r}22 / 200 \\
(11 \%)\end{array}$ \\
\hline
\end{tabular}

In tabel 3 word die ore wat met die tweede sifting faal, se otologiese diagnose uiteengesit. Uit tabel 3 blyk dit dat ' $n$ totaal van 39 uit 53 ore met die tweede sifting uitval $(73,6 \%)$. Van die 53 ore is slegs 17 as patologies geklassifiseer $\{32,1 \%\}$.

Daar kan dus gesê word dat 'n totaal van 17 ore, vanuit die aanvanklik getoetste populasie $\{8,5 \%\}$, beide die opvolgtoetsing en otologiese diagnose gefaal het. Wanneer hierdie persentasie vergelyk word met ander populasies van 'n gemiddelde sosio-ekonomiese status, is dit duidelik dat hier 'n hoë voorkoms van middeloorprobleme is. Die volgende voorkomssyfers van otitis media is hier tersaaklik: $2 \%$ (Amerika), 4,1\% (Rusland) en $1 \%$ (Denemarke) (Hinchcliffe in
Northern en Downs, 1984). Wanneer dit egter vergelyk word met die voorkoms onder hoërisikogroepe, byvoorbeeld Indo-Chinese vlugtelingkinders $(68,8 \%)$, is die voorkoms laag (Corth en Harris, 1984). Dit wil dus voorkom asof die voorkoms van middeloorprobleme by diê groep graad 1 en 2 leerlinge van Pretoria, hoër is as in ander gemiddelde sosio-ekonomiese status populasies, maar laer is as die insidensie in hoërisikogroepe.

Wanneer die voorkomssyfers van middeloorprobleme by skool $1\{11 \%)$ en by skool $2(6 \%)$ bestudeer word, blyk dit dat die resultate van skool 2 effens beter is. Op die $1 \%$ peil van betekenis is hierdie verskil egter nie statisties beduidend nie. Die moontlike redes vir die bevinding is reeds genoem.

Tabel 4: Die otologiese diagnose van die ore wat met die opvolgimmittansiemeting slaag.

\begin{tabular}{|c|c|c|c|}
\hline & \multirow{2}{*}{$\begin{array}{c}\text { OPVOLG- } \\
\text { SIFTING } \\
\text { SLAAG }\end{array}$} & \multicolumn{2}{|c|}{$\begin{array}{l}\text { OTOLOGIESE } \\
\text { DIAGNOSE }\end{array}$} \\
\hline & & $\begin{array}{l}\text { PATOLO- } \\
\text { GIES }\end{array}$ & NORMAAL \\
\hline $\begin{array}{l}\text { Skool 1 } \\
\mathrm{N}=29\end{array}$ & $\begin{array}{c}9 / 29 \\
\mid 31 \%)\end{array}$ & $\begin{array}{c}1 / 29 \\
\{3,4 \%\}\end{array}$ & $\begin{array}{c}8 / 29 \\
(27,6 \%)\end{array}$ \\
\hline $\begin{array}{l}\text { Skool } 2 \\
N=24\end{array}$ & $\begin{array}{c}5 / 24 \\
(20,8 \%)\end{array}$ & $\begin{array}{c}1 / 24 \\
(4,2 \%\}\end{array}$ & $\begin{array}{c}4 / 24 \\
(16,7 \%)\end{array}$ \\
\hline $\begin{array}{l}\text { Totaal: } \\
\text { (Opvolgsifting) } \\
\mathrm{N}=53\end{array}$ & $\begin{array}{c}14 / 53 \\
\{26,4 \%\}\end{array}$ & $\begin{array}{c}2 / 53 \\
(3,8 \%)\end{array}$ & $\begin{array}{c}12 / 53 \\
(22,6 \%)\end{array}$ \\
\hline $\begin{array}{l}\text { Totaal: [Uit totale } \\
\text { populasie) } \\
\mathrm{N}=200\end{array}$ & $\begin{array}{c}14 / 200 \\
(7 \%)\end{array}$ & $\begin{array}{c}2 / 200 \\
(1 \%)\end{array}$ & $\begin{array}{c}12 / 200 \\
(6 \%)\end{array}$ \\
\hline
\end{tabular}

In tabel 4 word die ore wat die tweede sifting slaag, se otologiese diagnose uiteengesit. Uit tabel 4 blyk dit dat 'n totaal van 14 uit 53 ore, die tweede sifting slaag $(26,4 \%)$. Uit die 14 ore, is slegs 2 as patologies geklassifiseer tydens die otologiese ondersoek $(14,3 \%)$, terwyl 12 ore $(85,7 \%)$, normaal was. Twee van die ore wat wel afwykend was volgens die otologiese diagnose is as normaal geklassifiseer tydens die opvolgsifting. Die een oor het ' $n$ 'herstelde perforasie gehad en die ander oor was atelektaties. Dit gebeur met ander woorde relatief selde dat ' $n$ persoon nie op oudiologie. se siftingstoetse uitval nie, maar dan wel as patologies geklassifiseer word $\{1 \%\}$.

Tabel 5: Otologiese ondersoek

\begin{tabular}{|l|c|}
\hline TIMPANIESE MEMBRAAN & TOTAAL \\
\hline Normaal & $181 / 200$ \\
$\mathrm{~N}=200$ & $(90,5 \%)$ \\
\hline Geskend & $8 / 200$ \\
$\mathrm{~N}=200$ & $\{4 \%\}$ \\
\hline Kliniese otitis media & $11 / 200$ \\
$\mathrm{~N}=200$ & $\{5,5 \%\}$ \\
\hline
\end{tabular}

In tabel 5 word die resultate van die otologiese ondersoek uiteengesit. Uit tabel 5 blyk dit dat vanuit 'n aanvanklik getoetste populasie van 200 ore, $4 \%$ 'n geskende timpaniese membraan en $5,5 \%$ kliniese otitis media het. Sou hierdie persentasies vergelyk word met resultate van soortgelyke 
studies, wil dit voorkom asof die prevalensie van middeloor. probleme hier relatief laag is. Hier kan die studie van Johnson $\{1970\}$ as voorbeeld genoem word. In die betrokke studie is 3000 Indiaanse kinders betrek. ' $n$ Voorkomssyfer van $7 \%$ gevalle met chroniese otitis media en $8 \%$ gevalle met te. kens van vorige middeloorpatologie is gevind. In teenstelling hiermee toets Fiellau-Nikolajsen $\{1979\}$ Kaukasiese kinders en vind ' $n$ baie lae voorkoms van $0,8 \%$ defekte van die timpaniese membraan. Dit wil dus voorkom asof die proefpersone in hierdie studie, in vergelyking met 'n hoë. risikogroep kinders, nie 'n abnormale hoë voorkoms van middeloorprobleme toon nie.

Tabel 6: Sensitiwiteit en spesiwiteit: Siftingsimmittansieresultate en otoskopiese ondersoek

\begin{tabular}{|c|c|c|c|}
\hline $\begin{array}{l}\text { SIFTINGS- } \\
\text { TOETS }\end{array}$ & PATOLOGIES & NORMAAL & TOTAAL \\
\hline $\begin{array}{l}\text { Positief } \\
\text { Negatief } \\
\text { Totaal }\end{array}$ & $\begin{array}{rc}17 & |\mathrm{a}| \\
2 & |\mathrm{c}| \\
19 & |\mathrm{a}+\mathrm{c}\rangle\end{array}$ & $\begin{array}{cc}22 & (\mathrm{~b}) \\
12 & (\mathrm{~d}) \\
34 & (\mathrm{~b}+\mathrm{d})\end{array}$ & $\begin{array}{l}39 \\
14 \\
53 \\
(a+b+c+d)\end{array}$ \\
\hline
\end{tabular}

Sensitiwiteit: $a /(a+c)$

$$
89,5 \%
$$

Spesiwiteit: $d /(b+d)$ (Frankenburg in Northern en Downs, 1984)

$35,3 \%$

In tabel 6 word die sensitiwiteit en spesiwiteit van die immit. tansiesiftingstoets bereken. Dit is dus duidelik dat hoewel die sensitiwiteit hoog is $(89,5 \%)$, is die spesiwiteit te laag $\{35,3 \%\}$ :

Die vraag ontstaan nou of die spesiwiteit van die immittansiesiftingstoets nie sal verbeter indien die akoestiese refleks nie as siftingskriterium gebruik is nie. Die rede hiervoor is omdat so 'n groot persentasie kinders ten spyte van 'n tipe A-tim. panogram, 'n afwesige akoestiese refleks toon en dus die siftingstoetsing faal. In so 'n geval kan die resultate soos volg getabelleer word:

Tabel 7: Sensitiwiteit en spesiwiteit: Timpanogramme en otoskopiese ondersoek

\begin{tabular}{|c|c|c|c|}
\hline $\begin{array}{l}\text { SIFTINGS- } \\
\text { TOETS }\end{array}$ & PATOLOGIES & NORMAAL & TOTAAL \\
\hline $\begin{array}{l}\text { Positief } \\
\text { Negatief } \\
\text { Totaal }\end{array}$ & $\begin{array}{rc}14 & |a| \\
2 & |c\rangle \\
16 & |a+c\rangle\end{array}$ & $\begin{array}{cc}16 & (\mathrm{~b}) \\
12 & (\mathrm{~d}) \\
28 & (\mathrm{~d}+\mathrm{b})\end{array}$ & $\begin{array}{l}30 \\
14 \\
44(a+b+c+d)\end{array}$ \\
\hline
\end{tabular}

Sensitiwiteit: $a /(a+c)$ $87,5 \%$

Spesiwiteit: $d /(b+d)$ (Frankenburg in Northern en Downs, 1984)

$42,9 \%$

In tabel 7 word die sensitiwiteit en spesiwiteit van die immittansiesiftingstoets bereken waar reflekse nie as matstaf gebruik word nie. Die afleiding kan dus gemaak word dat die spesiwiteit van die immittansiesiftingstoets wel van 35,3 na 42,9 verbeter het, maar dat dit steeds baie laag is. Dit is nogtans bemoedigend dat kinders wat middeloorprobleme toon selde nie deur middel van immittansiesiftingstoetse ge. identifiseer kan word nie.

\section{GEVOLGTREKKINGS}

In teenstelling met die algemene opvatting dat daar 'n hoër voorkoms van middeloorprobleme in 'n laer sosio-ekonomiese gebied as in 'n hoër sosio-ekonomiese gebied sal wees (Klein, 1978) het dié studie dit as onwaar bewys. Feitlik ewe veel leerlinge uit beide die hoë en lae sosio-ekonomiese omgewing faal die eerste, sowel as die tweede siftingsprosedure. Redes hiervoor kan onder andere klein verskille in sosio-ekonomiese status onder blankes, goeie mediese en oudiologiese dienste ook in die laer sosio-ekonomiese gebied en die effens jonger ouderdomme van leerlinge in skool 2 wees.

Ten opsigte van die voorkoms van middeloordisfunksie (oudiometries bepaal) faal ' $n$ totaal van $19,5 \%$ die eerste, sowel as die tweede oudiologiese sifting. Word dit vergelyk met resultate van soortgelyke studies, wil dit voorkom asof die prevalensie van middeloordisfunksie by dié 2 groepe kinders nie kommerwekkend hoog is nie. Redes hiervoor kan die gereelde skoolmediese, sowel as oudiologiese dienste waaroor hierdie skole beskik, wees. 'n Totaal van 17 ore $(8,5 \%)$, vanuit die aanvanklik getoetste populasie, faal beide die opvolgtoetsing en die otologiese diagnose. Verder was daar geen statisties beduidende verskille tussen die twee groepe persone nie.

Ten opsigte van die aard van die middeloorpatologie het $4 \%$ 'n geskende timpaniese membraan en het $5,5 \%$ kliniese otitis media. In vergelyking met ander studies wil dit voorkom asof hierdie proefpersone in vergelyking met hoërisiko. groepe nie ' $n$ hoë voorkoms van middeloorprobleme vertoon nie (Johnson, 1970): Dit blyk egter dat die voorkoms wel hoër is as ander Kaukasiese populasies (Fiellau-Nikolajsen, 1979).

Ten opsigte van ' $n$ vergelyking tussen die mediese en oudiologiese resultate, blyk dit dat die sensitiwiteit van die immittansiemetings goed is, maar die spesiwiteit baie laag is $(35,3 \%)$. Indien akoestiese reflekse nie as siftingskriterium gebruik word nie, verbeter die spesiwiteit na $42,9 \%$.

Hierdie studie verskaf belangrike inligting aangesien dit die eetrste keer is wat so 'n studie onder Kaukasiërs in Suid. Afrika uitgevoer is. Die voorkomsfrekwensie van $9,5 \%$ vir middeloordisfunksie soos in dié studie verkry is, sal waarskynlik wissel in ander populasies, geografiese areas, ouderdomsgroepe, ensovoorts, maar 'n prevalensiesyfer vir 'n groep graad 1 en 2 blanke kinders is nou beskikbaar.

\section{VERWYSINGS}

Badenhorst, M.S. Persoonlike onderhoud. Departement Stads-. en Streekbeplanning, Universiteit van Pretoria, 1987.

Barrett, K.A. Hearing and immittance screening of school-age children. In Katz, J. (red.) Handbook of Clinical Audiology. Baltimore: Williams \& Wilkins, 1985.

Brooks, C.N. School screening for middle ear effusions. The Annals of Otology, Rhinology and Laryngology, Suppl. 25(2), 223-2238, 1976.

Corth, S.B. \& R.W. Harris. Incidence of middle ear disease in IndoChinese refugee schoolchildren. Audiology, 23, 27-37, 1984.

Feldman, A.S. \& L.A. Wilber. Acoustic Impedance and Admittance. Baltimore: Williams \& Wilkens, 1977.

Fiellau-Nikolajsen, M. Tympanometric prediction of the magnitude of hearing loss in preschool-children with secretory otitis media. Scandinavian Audiology, Supplementum 17,
$68-72,1979$.

Hugo, R. Normatiewe evaluasie van otitis media as sekondêre patologie. Suid-Afrikaanse Tydskrif vir Opvoedkunde, 5, $83-88,1984$. 
Jerger, J. Clinical experience with impedance audiometry. Archives of Otolaryngology, 92, pp. 311-324, 1970

Johnson, R.L. A abbreviated impedance bridge technique for school screening. In Feldman, A.S. \& L.A. Wilber (reds.) Acoustic Impedance and Admittance. Baltimore: Williams and Wilkens, 1970

Klein, J.O. Epidemiology of otitis media. In Harford, E.R., F.H. Bess, C.D. Bluestone, J.O. Klein (reds.): Impedance Screening of Middle Ear Disease in Children. New York: Grune \& Stratton, 1978 .

Lewis, N. Otitis media and linguistic incompetence. Archives of Otolaryngology, 192, 387-390, 1976

McWilliams, B.J., H.L. Morris \& R.L. Shelton. Cleft Palate Speech. St. Louis: The CV Mosby Company, 1984.

Moller, P. Incidence and time course of otitis media in children.
Audiology in Practice, 1\{3\}, 1, 1985.

Northern J.L. \& M.P. Downs. Hearing in Children. Baltimore: The Williams \& Wilkens Company, 1984.

Prescod, S.V. Audiological Handbook of Hearing Disorders. New York: Litten Education Publishing Inc., 1978.

Smit, G.J. Navorsingsmetodes in die Gedragswetenskappe. Pretoria: HAUM opvoedkundige uitgewers, 1983.

Van Berge, M.M. Die Sosio-ekonomiese Status van Woongebiede in Pretoria. Ongepubliseerde skripsie, Universiteit van Pretoria, 1982

Voogt, G.R., Halama, A.R. \& Van der Merwe, C.A. Immittance screening in black preschool children attending day-care centres. Audiology, 25, 158-164, 1986.

Wilson, J. Deafness in developing countries. Archives of Otolaryngology, 3[1\}, pp. 2-9, 1985. 


\section{NEW - A MOMENT OF TRUTH FROM AMTRONIX}

\section{OTICON I52 CANAL HEARING AID}

Available in Standard (Modular) and custom made.
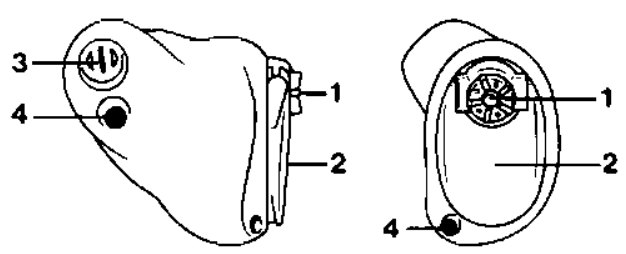

1. Volume control button (with on/off function) Red dot: Right version.

Blue dot: Left version.

2. Battery compartment (below lid).

3. Sound outlet.

4. Vent opening (In Custom version).
The 152 comes standard with three audiological controls as shown in fig. A: A-GRAM control = low frequency adjustment (green arrow and dots).

$\mathrm{dB} \mathrm{HL}$ control = output/gain adjustment (red arrow and dots).

Feedback control (FC) = high frequency adjustment (orange arrow and dots). Fig. B shows minimum $\&$ maximum of controls.

State of the Art Technology for the year 1990 available from Amtronix in 1988.

The almost impossible made possible, thanks to Oticon!

\section{COMPUTERIZED INSERTION GAIN OPTIMIZER}

Features:

* The sure way to the right results.

* Read in Personal Patient and Audiogram Data.

* Measure open ear and occluded ear gain.

* Compare insertion gain curves and select hearing aid.

* Programme alternate test procedures; if needed.

* Get it right first time.

\section{THE IGO 1000 SYSTEM OFFERS YOU}

* A compact, easy-to-use diagnostic and treatment package.

* Complete test capability.

* High resolution, full colour monitor and printouts.

* High speed and extreme test accuracy.

* Efficient, easy-access storage of patient data.

* A modern, ergonomic design for maximum user comfort.

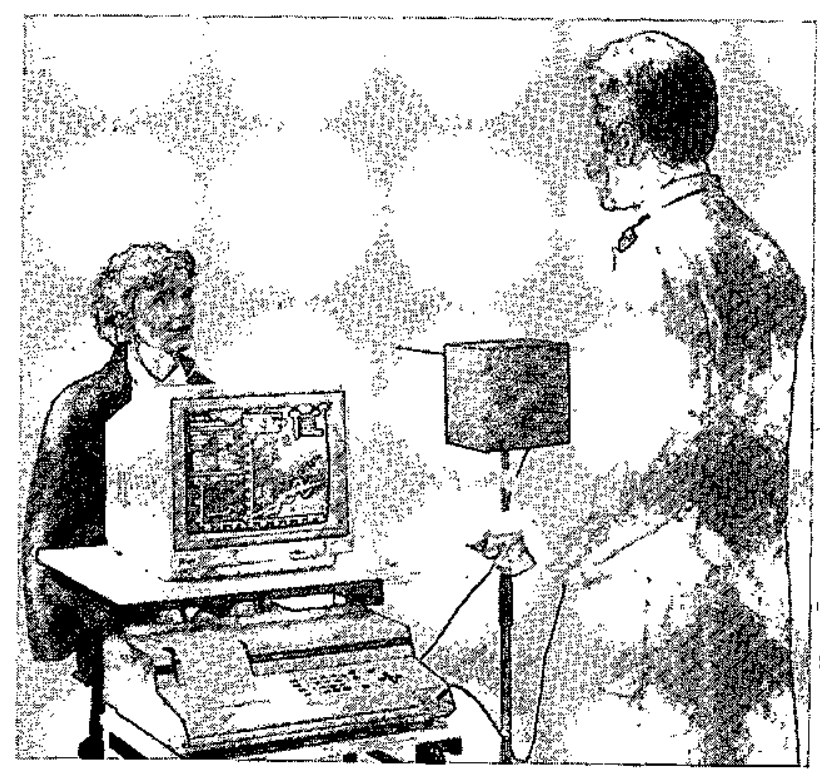

\section{DIAGNOSTIC AUDIOMETRY}

The friendly Midimate 602 Diagnostic Audiometer for Audiologists demanding capability, simplicity and efficiency.

\section{Features:}

* Brief automatic check at start-up.

* Fast menu-driven setup of your own test.

* 5 preprogrammable test setups for in test. ble in the daily routine.

* Simple and logical multilingual menu-driven display dialogue makes the Midimate 002 easy to learn and easy to use.

* Transflective blacklighted display is easily readable under technology enlarges the viewing angle readable under any lighting conditions while supertwist

* Few operator controls all logically located on front panel for optimal operation convenience and accuracy.

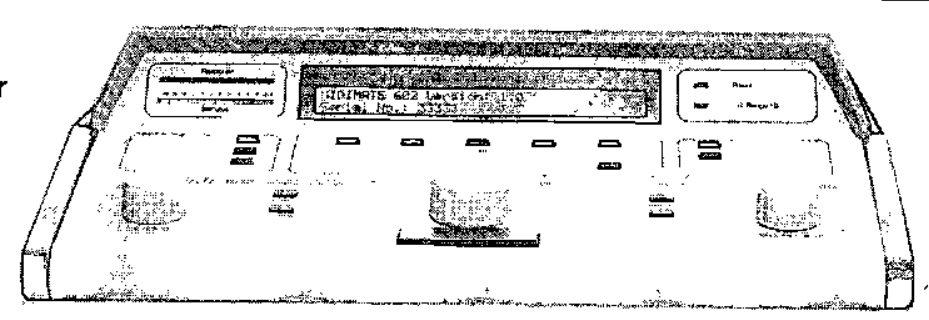

